\title{
Resistance to dislodgement: habitat and size- specific differences in morphology and tenacity in an intertidal snail
}

\author{
Geoffrey C. Trussell ${ }^{1, *}$, Amy S. Johnson ${ }^{2}$, Seri G. Rudolph ${ }^{2}$, Edward S. Gilfillan ${ }^{1}$
}

${ }^{1}$ Environmental Studies Program and ${ }^{2}$ Department of Biology, Bowdoin College, Brunswick, Maine 04011, USA

\begin{abstract}
An organism's ability to persist on wave-swept rocky shores is determined, in part, by its ability to resist dislodgement by waves. Resistance to dislodgement depends on hydrodynamic forces and on the ability of an organism to resist those forces by adhering to the substratum. In intertidal snails the structure upon which waves act is the shell and the structure that adheres is the muscular foot. We quantified: (1) shell size (defined as the maximum projected surface area, MPSA); (2) shell shape; (3) foot area; (4) maximum force to dislodge a snail in shear; and (5) tenacity (force per foot area required to dislodge) of the herbivorous intertidal snail Littorina obtusata. We compared individuals that were collected from habitats characterized by differences in exposure to waves. Wave-exposed snails were smaller (lower average MPSA). In addition, snails at the wave-exposed site were shorter, and had larger foot area and greater dislodgement force than did protected snails of similar MPSA. The greater dislodgement force at the exposed site was due to larger foot area, not to greater tenacity. In fact, sizespecific tenacity of snails from the protected habitat was greater. Within each site, shape changed with size. Although shell width, length and MPSA scaled isometrically, shell height did not; longer shells were relatively short. Nor did foot area scale isometrically with MPSA; larger snails had relatively smaller foot areas. Assuming that MPSA is directly proportional to speed-specific drag, which is reasonable for bluff bodies, we found that dislodgement force was proportional to drag. This result suggests that increasing tenacity compensated for underscaling of foot area. In fact tenacity did increase with foot area, although only significantly so at the wave-exposed site
\end{abstract}

\section{INTRODUCTION}

Environmental heterogeneity in the form of wave exposure has profound effects on rocky intertidal communities (Sousa 1979, 1984, Paine \& Levin 1981) and the individuals inhabiting them (Denny 1983, 1985, Denny et al. 1985, Denny \& Gaines 1990). Understanding the direct and indirect effects of wave activity on intertidal communities is an important goal of marine ecology (Menge \& Sutherland 1976, 1987). The degree to which wave exposure influences intertidal communities may reflect the vulnerability of the component species to dislodgement. By directing the adaptive or evolutionary strategies of intertidal organisms,

\footnotetext{
- Present address: Virginia Institute of Marine Science, The College of William and Mary, Gloucester Point, Virginia 23062, USA
}

wave-induced dislodgement could be a primary determinant of persistence in intertidal environments. Differences in the behavioral, morphological, and physiological responses of intertidal organisms may result, in part, from differences among their respective wave-environments. A knowledge of how individuals respond to environmental heterogeneity is essential to an overall understanding of intertidal community dynamics.

Waves can dislodge intertidal organisms by imparting lift, acceleration reaction, and drag forces (Denny et al. 1985). Mobile intertidal organisms, such as the littorinid snail used in this study, can resist dislodgement by: (1) using sheltered microhabitats; (2) having a shell morphology that reduces drag; and (3) adhering to the substratum. Although not investigated in this study, the use of sheltered microhabitats (e.g. cracks and crevices) has been suggested as an important 
behavioral response reducing the effects of waveimparted forces and the likelihood of dislodgement (Denny et al. 1985, Witman 1985, Etter 1988a, Stebbins 1988). Shell morphology may directly influence the amount of wave-imparted forces experienced by an organism by limiting exploitation of sheltered microhabitats. Both shell size and shape may limit the amount of sheltered microhabitats available to a mobile individual thereby forcing it to bear the brunt of prevailing flow (Kohn 1971, Emson \& Faller-Fritsch 1976, Raffaelli \& Hughes 1978). Aspects of shell morphology may also have a direct role in reducing the likelihood of dislodgement by mitigating the effects of wave-imparted drag forces. First, differences in shell shape may change the shell's coefficient of drag. Second, a reduction in the amount of shell surface area projected into flow may also reduce the amount of wave-imparted drag experienced by the organism.

Shell morphology of various intertidal organisms has been shown to vary along a gradient in wave exposure. For example, Stebbins (1988) found that the chiton Katharina tunicata is typically smaller on waveexposed shores, and Branch \& Marsh (1978) found that limpets have shell attributes that reduce drag. Denny (1989) documented a case in which limpet shells can reduce drag in the laboratory but concluded that the conditions favoring this scenario are unlikely to occur in the field.

The foot of littorines functions in locomotion and adherence to the substratum. The ability of the foot to adhere can be influenced by the surface area of the foot and the thickness and strength of the foot mucus. However, the relative importance of each of these features in facilitating adhesion to the substratum is still debated and poorly understood (Branch \& Marsh 1978, Grenon \& Walker 1981, Etter 1988a). Foot area, as well as tenacity (dislodgement force per foot area), has been shown to vary with wave exposure (Kitching et al. 1966, Miller 1974, Branch \& Marsh 1978 , Etter 1988a). Etter (1988a), for example, found that Nucella lapillus from wave-exposed shores had larger foot areas than conspecifics from more protected shores.

The work presented here focuses on wave-generated drag as the primary force involved with the dislodgement of Littorina obtusata (Denny et al. 1985). Because dislodgement from the substratum may interfere with a variety of life history processes, including an individual's ability to forage or reproduce successfully, the ability to resist wave-induced dislodgement should have important implications for individual snails as well as for community structure (Menge 1974 , Etter 1988a, 1989, Judge 1988, Dudgeon \& Johnson 1992). However, wave intensity varies between shores and may have relatively benign effects in more pro- tected or sheltered environments. With this in mind we asked 2 questions: (1) Does shell and foot morphology differ between a wave-exposed and protected shore? (2) If so, do snails from a wave-exposed shore have shell morphologies that reduce drag, as well as foot areas and tenacities that increase the force necessary to dislodge them?

\section{METHODS}

Field sites. Field sites were chosen to represent 2 extremes in wave-exposure: highly wave-exposed at Pemaquid Point, Maine (Menge 1976, 1978, Lubchenco \& Menge 1978), and protected at Potts Point, Maine, USA. Data from previous work, qualitative assessments, and Dalby et al.'s (1978) biological criteria, modified for Maine's coastline (Whalon 1989), were used to determine the relative wave-exposure of each site.

Pemaquid Point is a peninsula that projects directly into the Gulf of Maine and is characterized by extremely high wave action (Menge 1976, 1978, Lubchenco \& Menge 1978). Winter storm surges can be particularly intense (Trussell pers. obs.). The study site, which encompassed an area of approximately $15 \mathrm{~m}^{2}$, was located in a gully between a table and wall of rock, the table being more seaward. The surface of the rock wall consisted of exposed granite and patchy populations of the barnacle Semibalanus balanoides and blue mussels Mytilus edulis. Individual mussels and barnacles were extremely small at this site $k 1.5 \mathrm{~cm}$ in length). The dominant invertebrates located within the study area were Littorina obtusata, Nucella lapillus and Acmea testudinalis. At low tide, most $L$. obtusata were found in or near cracks and crevices, and relatively few could be found actively crawling on bare substratum.

Potts Point is located on a small peninsula that extends out into a well protected bay. Wave action typically consisted of small ripples, and even on stormy days there was little wave action (Trussell pers. obs.). The study site was a $10 \mathrm{~m}^{2}$ rectangle located in the lower-middle portion of the intertidal zone. Granite comprised approximately $95 \%$ of the available substratum and was completely blanketed by Ascophyllum nodosum. The dominant macrofauna were Littorina littorea, L. obtusata, Mytilus edulis, and green crabs Carcinus maenas. Nucella lapillus were observed occasionally. L. abtusata were found primarily on $A$. nodosum and resembled the air bladders of this species. C. maenas were often seen and, although no instances of predation were observed in the field, they are known to prey on L. obtusata (Seeley 1986, Trussell pers. obs.). 
Snails were collected in mid-March 1990 from rectangular plots previously established within each study area. To collect snails, 3 swaths $(5 \mathrm{~m}$ long $x$ $0.30 \mathrm{~m}$ wide at Pemaquid Point, $2 \mathrm{~m}$ long $\times 0.30 \mathrm{~m}$ wide at Potts Point) were set up within each rectangular plot. The location of each swath was determined by use of a random number generator. A transect line was set in the middle of each swath and 7 to 10 individuals were collected at haphazardly chosen intervals within each swath along the entire length of each transect. Snails used for the laboratory experiments were randomly sampled from the pool of individuals collected.

Laboratory measurements. Littorina obtusata collected from each site (21 and 20 from the waveexposed and protected shores respectively) were maintained in recirculating seawater tables (temperature $=9$ to $10^{\circ} \mathrm{C}$ ) for $1 \mathrm{wk}$ until the following measurements were made.

Shell shape and size: This study focused on drag as the force most likely to influence the dislodgement of Littorina abtusata (Denny et al. 1985). Therefore, to identify the important morphological characteristics associated with drag we used the drag equation (Vogel 1981):

$$
\text { Drag }=0.5 C_{D} \rho S U^{2}
$$

where $C_{D}=$ the coefficient of drag, an empirical parameter that is influenced by a number of factors, including shape and the Reynolds number (see Vogel 1981 for description of Reynolds number); $\rho=$ the density of seawater; $S=$ maximum projected surface area perpendicular to flow (MPSA); and $U=$ water velocity.

Mean and maximum water velocity, $U$, is expected to be greater at the wave-exposed site (Denny 1985, Denny et al. 1985, Denny \& Gaines 1990) than at the protected site because the 2 sites represent extremes in wave energy. Therefore, increased water velocity will play a role in increasing drag on Littorina obtusata on the wave-exposed shore. Examination of the drag equation (Eq. 1) reveals that snails can reduce the drag they experience in a given flow by: (1) reducing the $C_{D}$ of the shell, possibly by some change in shape, or (2) reducing MPSA.

Shell shape: Shell shape was quantified by comparisons of height, length and width of shells (measured as illustrated in Fig. 1) with each other as well as with the maximum projected surface area of the shell (described below).

Shell size and maximum projected surface area: Waves can strike from any direction relative to snails attached to a substratum. For this reason, we chose the maximum projected surface area of the shell as the orientation that would expose the shell to the greatest drag. MPSA was also used as our measure of shell size

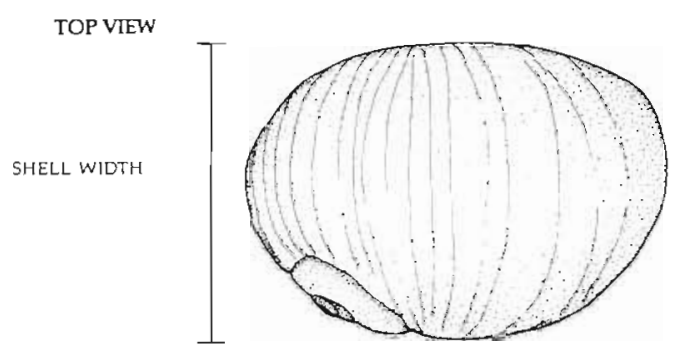

SIDE VIEW

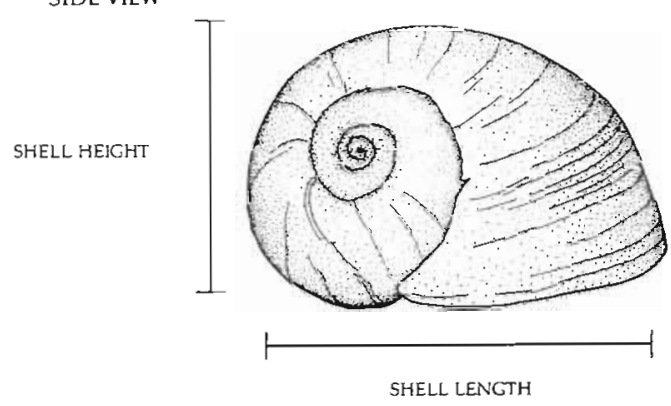

Fig. 1 Littorina obtusata. Diagram indicating how length, height, and width were measured on snail shells

for comparisons of foot area, force to dislodge and tenacity between sites (descriptions of these measurements are below). MPSA was determined from photographs by cutting and weighing tracings of the outline of the shell shown in the side view in Fig. 1.

Foot area: This study focuses on foot area as the variable most likely to be associated with a snail's ability to resist dislodgement. Prior to determining foot area, snails were numbered and a small wire hook was glued with marine epoxy to the highest point of the snail's shell. Snails were then left undisturbed for $48 \mathrm{~h}$. No adverse effects appeared to result from these procedures. After $2 \mathrm{~d}$, the foot area of each snail was determined by placing the snails in a holding tank with a transparent bottom. The hooks on each snail were tapped in a direction similar to the pulling action of the micromanipulator (used in the dislodgement force measurements described below) to induce maximum adhesion. The foot area of each snail was traced on a sheet of acetate taped to the bottom of the tank. This measurement was performed 4 times for each snail and the average of the 4 foot areas measured for each snail was used in subsequent analyses. Snails were subsequently placed on a plexiglas platform for the dislodgement experiment (see below). The area of the traced ellipses was determined using the cut-andweigh method.

Dislodgement force and foot tenacity: Tenacity is defined in this study as the dislodgement force per unit foot area in contact with a surface $\left(\mathrm{N} \mathrm{m}^{-2}\right)$ and was 
determined by dividing each snail's maximum shear dislodgement force by its mean foot area (obtained as described above).

To determine dislodgement force, snails were placed on a clean, smooth plexiglas platform held by a micromanipulator and were allowed to move towards a piece of sea lettuce Uiva sp. placed in front of them. Oral contact with the sea lettuce was not allowed because this could have altered adhesive abilities. Once the monofilament line connecting the snail's hook to a strain gauge beam was pulled taut, a small force was applied to the snail by moving its platform slowly away from the strain gauge beam by the use of the micromanipulator. This small force caused the snail to clamp down tightly (Etter 1988a, Stebbins 1988, Trussell pers. obs.). The shape of the snail's foot was also visually checked to determine if it was adhering tightly. When adhering tightly to a substratum, snails form a small ellipse directly beneath the aperture with their foot. Although this shape reduces the possible surface area of the foot in contact with a surface relative to foot surface area during movement, it has been shown to promote greater adhesion (Miller 1974, Branch \& Marsh 1978, Grenon \& Walker 1981, Etter 1988a).

Once adherence and foot shape were confirmed, force was increased gradually using the micromanipulator to move the platform away from the strain gauge beam. The shear force generated by the micromanipulator was increased until the snail was dislodged and the corresponding dislodgement force was read from the chart recorder. The procedure was performed 4 times for each snail, the maximum shear force determined and used in all subsequent analyses. We call this maximum force the dislodgement force. All individuals from both sites were tested on 4 consecutive days with a period of $24 \mathrm{~h}$ between each test.

Scaling of shell and foot area: In this paper, morphological scaling examines the allometry between: (1) maximum projected surface area of the shell and the linear dimensions of that shell (length, width and height as indicated in Fig. 1); (2) MPSA and foot area; and (3) shell length and height. Scaling relationships were determined by applying standard allometric analysis (Schmidt-Neilsen 1984). Scaling coefficients were quantified by determining the slope of log-log plots. The equation for the line of this log-log plot is:

$$
\log (Y)=\log (a)+b \log (X)
$$

where $Y=$ foot area or one of the linear dimensions of the shell; $X=$ MPSA or shell length; $a=$ the intercept and $b=$ the slope of this linear equation. This slope $b$, as shown by taking the antilog of Eq. (2):

$$
Y=a(X)^{b}
$$

is the exponent that expresses the allometric relationship between the rate of increase in $Y$ per unit increase in $X$. For example, when $b=1.0$, foot area is scaled to be isometrically similar with respect to MPSA and length of shells is scaled to be isometrically similar with respect to shell height. When $b=0.5$ then the linear dimensions of the shell are scaled to be isometrically similar with respect to MPSA.

The interpretation of these morphological scaling relationships is based on the assumption that tenacity (dislodgement force per foot area) is independent of foot area. We examined this assumption by determining the allometric coefficient relating maximum dislodgement force to foot area. If tenacity is independent of foot area then $b=1$; if $b>1$ then larger foot areas have greater tenacity. Similarly, if drag (Eq. 1) is the important dislodgement force for these snails then the allometric coefficient relating dislodgement force to MPSA should also equal $1_{i}$ if $b>1$ then risk of dislodgement, for a snail exposed to a given flow, decreases as snails grow.

Standard least squares linear regression analysis will generally underestimate the slope, $b$, for allometric relationships with a low $R^{2}$ because of error in the measurement of the independent parameter, MPSA, shell length or mean foot area in our case (LaBarbera 1989). To estimate the effect of this error, the reliability ratio, $\kappa$ (Fuller 1987), can be estimated by using the correlation, $R$, between sequential measurements of the independent variable, where $\kappa=R$. The corrected slope, $\beta$, can be determined by multiplying the uncorrected slope of the $\log$ - $\log$ plots by $1 / k$ (e.g. Dudgeon \& Johnson 1992).

To determine $k$ for MPSA and shell length we made 2 completely independent determinations of these variables (using the methods described above) on 10 snails over the size range represented by our data and calculated the regression of the first with the second determination of these variables. The value $1 / \kappa$ obtained for MPSA and shell length, as determined from the $\mathrm{R}$ for this regression $\mathrm{R}=0.997$ and 0.999 , respectively), was less than 1.003 in both cases, which did not change the value of the slope that we obtained for our regressions.

To determine $k$ for mean foot area we made 8 tracings of the foot of 10 snails, 2 tracings $d^{-1}$ for $4 \mathrm{~d}$ in a row. We calculated the regression of the mean value for foot area obtained from the first 4 measurements with the mean value of the foot area obtained from the second 4 measurements. The value for $1 / k$ obtained for mean foot area, as determined from $\mathrm{R}$ for this regression $(R=0.75)$, was 1.33 . We calculated the corrected slope, $\beta$, by multiplying the uncorrected slope of the $\log -\log$ plot of dislodgement force as a function of mean foot area by $1 / k$. Statistical comparison of $\beta$ with 
a line of slope 1.0 was obtained using the following $t$-test (with $n-2$ degrees of freedom; Fuller 1987):

$$
t=(\beta-1.0) \mathrm{K} / \mathrm{SE}_{\mathrm{u}}
$$

where $\mathrm{SE}_{\mathrm{u}}$ = standard error of the uncorrected slope of the regression line. We calculated the corrected intercept by using the mean values of $\log X$ (foot area) and $\log Y$ (dislodgement force), and substituting the corrected slope, $\beta$, for $b$ in Eq. (2)

Statistical analyses. Prior to analyses, data were examined to determine if the assumptions of analysis of variance were met (Bartlett's test, $\mathrm{p}>0.05$; Underwood 1981). ANOVA, $t$-tests and linear regression analyses were performed using 'Systat' and 'StatView' software on a MacIntosh IIci. $t$-tests were used to compare the slopes of the log-log plots to a line with a slope of either 0.5 (for comparison of MPSA with the linear dimensions of the shell) or 1.0 (for all other comparisons). ANCOVA comparisons were performed using software programmed by R. Etter

\section{RESULTS}

\section{Shell size and shape}

With the exception of shell height at the protected site, the linear dimensions of the shell scaled isometrically with increasing size (MPSA) at both sites ( $b$ was not significantly different than 0.5 ; all $b$ between 0.45 and 0.54 , all $t_{18}$ or $19<2.1$, all $p>0.05$; Fig. $2 a$, b). At the protected site, shell height increased disproportionately less than isometrically with respect to MPSA $\left(b=0.42, t_{18}=-3.08, p<0.01\right.$; Fig. $\left.2 c\right)$. The relationship between shell height as a function of shell length shown in Fig. 3 indicates, however, that there actually was a change in size-related shell shape that occurred at both sites: longer shells were relatively short (at both sites $b<1$; protected: $b=0.77, t_{18}=-3.32, \mathrm{p}<$ 0.05 ; wave-exposed: $\left.b=0.80, t_{19}=-2.60, \mathrm{p}<0.05\right)$. Furthermore, while height changed with length at the same rate at both sites, shells from the waveexposed site were shorter for a given length (ANCOVA, Table 1; Fig. 3)

Shells of snails from the wave-exposed and protected sites differed in both size and shape. Snails at the wave-exposed site had a smaller mean size (mean MPSA $=0.46 \mathrm{~cm}^{2}$ ) than did those at the protected site (mean MPSA $=0.60 \mathrm{~cm}^{2}$; ANOVA: $F_{(1.39)}=21.4$, $\mathrm{p}=0.0001 \mathrm{l}$. While height, length and width changed with MPSA at the same rate at both sites and shells from both sites were the same width for a given MPSA, shells of a given size at the wave-exposed site were significantly longer and shorter than those from the protected site (ANCOVA, Table 1; Fig. 2b, c). (a)

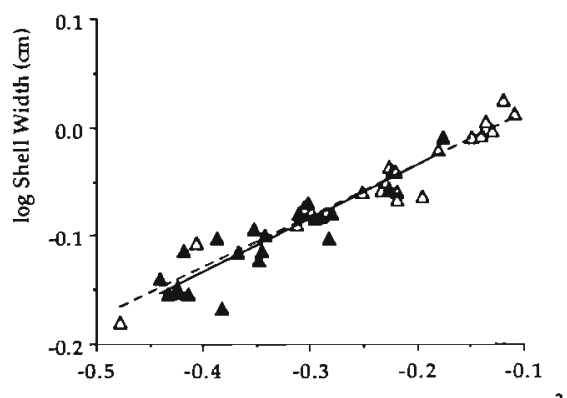

$\log$ Maximum Projected Surface Area (MPSA) $\left(\mathrm{cm}^{2}\right)$

(b)

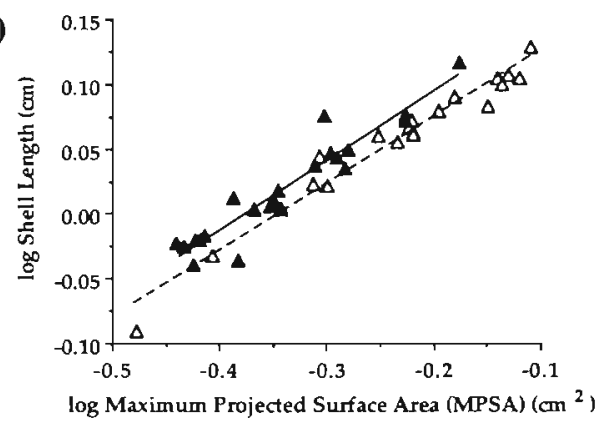

(c)

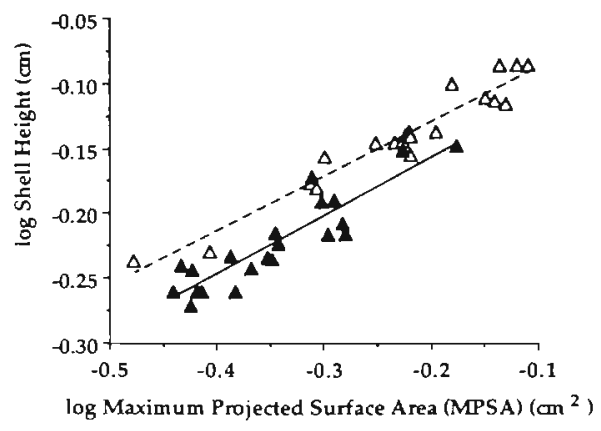

Fig. 2. Littorina obtusata. Log-log plots of (a) shell width, (b) shell length and (c) shell height (all in $\mathrm{cm}$ ) as a function of MPSA $\left(\mathrm{cm}^{2}\right)$ for snails from the protected site $\left(\Delta_{,-\cdots}\right)$ and the wave-exposed site $(\mathbf{\Lambda},-)$. Lines represent least squares regressions for data from each site. Within each plot the slopes of lines do not differ significantly; elevations of lines are significantly different for plots (b) and (c) but not for (a) (see Table 1 for ANCOVA and linear regression statistics)

\section{Foot area}

Foot area increased with MPSA at the same rate at each site (ANCOVA, Table 1; Fig. 4). At both sites the allometric coefficient for the relationship between MPSA and foot area was significantly less than 1 (protected: $b=0.83, t_{18}=-2.10, \mathrm{p}=0.05$; wave-exposed: $b=0.63$, $t_{19}=-3.08, p<0.01$ ) so that larger snails had disproportionately smaller foot areas for their size (MPSA) than did smaller snails. The foot area of a snail of a given size (MPSA) was greater at the wave-exposed site than at 


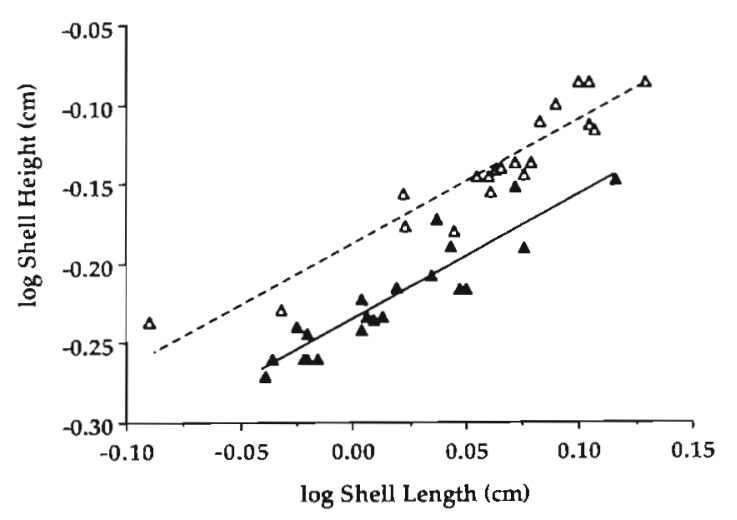

Fig. 3. Littorina obtusata. Log-log plot of shell height $(\mathrm{cm})$ as a function of shell length $(\mathrm{cm})$ for snails from the protected site $(\Delta,-\cdots)$ and the wave-exposed site $\left(\boldsymbol{\Lambda}_{1}--\right)$. Lines represent least squares regressions for data from each site. Slopes of lines do not differ significantly; elevations of lines are significantly different (see Table 1 for ANCOVA and linear regression statistics) the protected site (ANCOVA, Table 1; Fig. 4). These site-specific differences in foot area are also demonstrated by the results of ANOVA comparing mean foot area between sites: despite their smaller mean size (MPSA), snails at the wave-exposed site had larger mean foot area $\left(0.34 \mathrm{~cm}^{2}\right)$ than did those at the protected site $\left(0.28 \mathrm{~cm}^{2}\right.$; ANOVA: $\left.F_{(1,40)}=16.3, \mathrm{p}=0.0002\right)$.

\section{Dislodgement force and foot tenacity}

Dislodgement force increased with foot area at the same rate at each site (ANCOVA, Table 1; Fig. 5a); however, the maximum force to dislodge a snail with a given foot area was greater at the protected site than at the wave-exposed site (ANCOVA, Table 1; Fig. 5a). The latter result of the ANCOVA is supported by the results of ANOVA restricted to data in the range of overlapping foot area $\left(0.27 \mathrm{~cm}^{2}\right.$ to $\left.0.37 \mathrm{~cm}^{2}\right)$ comparing mean tenacity (force per foot area) between sites: mean tenac-

Table 1. Littorina obtusata. Results of $\log (Y)-\log (X)$ regression analyses for relationships between various attributes of shell morphology, foot morphology, and adhesive ability for wave-exposed ( $\mathrm{n}=21$ for all comparisons) and protected ( $\mathrm{n}=20$ for all comparisons) snails. Also shown are the results of an ANCOVA comparing the slopes ( $\mathrm{df}=1,37$ for all comparisons) and elevations ( $\mathrm{df}=1,38$ for all comparisons) of regression lines for wave-exposed and protected snails. The $E$ vs $P$ column indicates the direction of the significant difference in the elevations of the regression lines between the 2 populations. MPSA: maximum projected surface area; E: wave-exposed; P: wave-protected

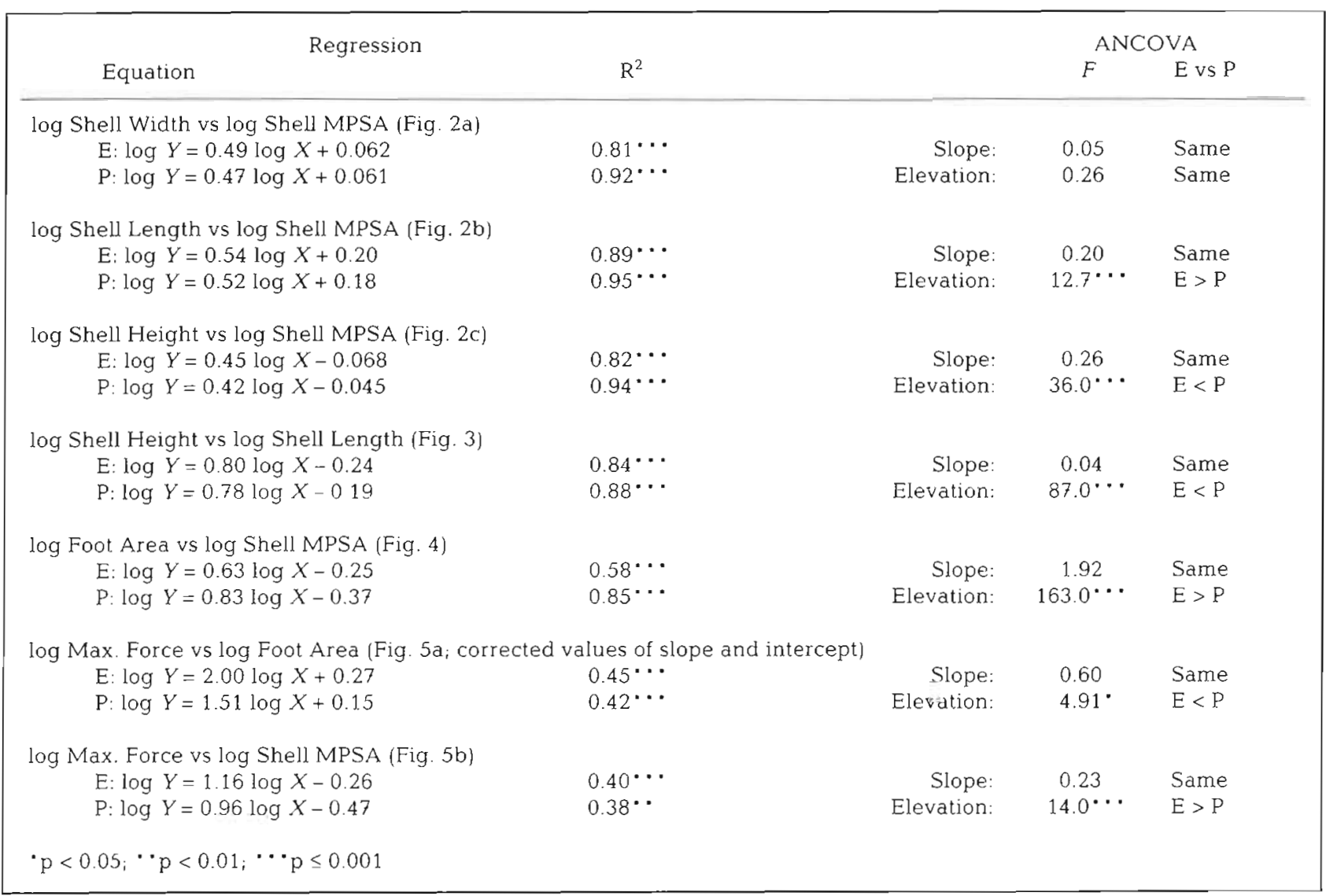




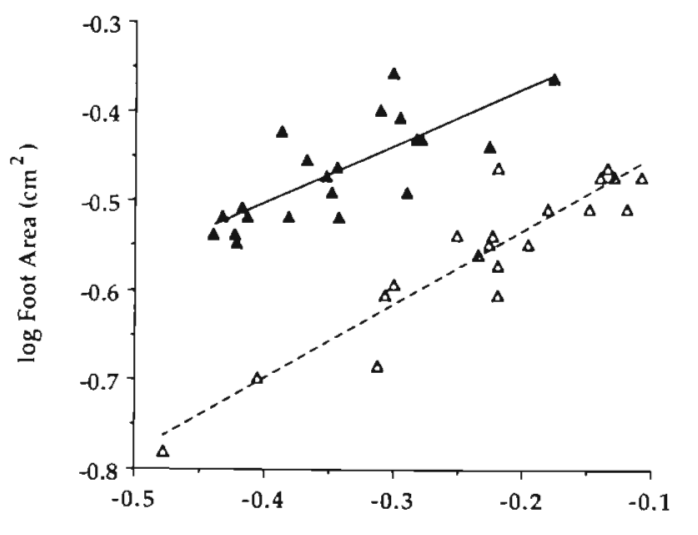

$\log$ Maximum Projected Surface Area (MPSA) $\left(\mathrm{cm}^{2}\right)$

Fig. 4. Littorina obtusata. Log-log plot of foot area $\left(\mathrm{cm}^{2}\right)$ as a function of MPSA $\left(\mathrm{cm}^{2}\right)$ for snails from the protected site $(\Delta,---)$ and the wave-exposed site $(\boldsymbol{\Lambda},-)$. Lines represent least squares regressions for data from each site. Slopes of lines do not differ significantly; elevations of lines are significantly different (see Table 1 for ANCOVA and linear regression statistics)

ity in this restricted range was greater at the protected site $\left(7.9 \times 10^{4} \mathrm{~N} \mathrm{~m}^{-2}\right)$ than at the wave-exposed site $\left(6.5 \times 10^{4} \mathrm{~N} \mathrm{~m}^{-2}\right.$; ANOVA: $\left.F_{(1.27)}=4.37, \mathrm{p}<0.05\right)$.

Differences in tenacity did appear to occur as a function of foot area at the wave-exposed site, but not at the protected site. At the protected site the allometric coefficient for the relationship between mean foot area and dislodgement force (Fig. 5a) was not significantly different from $1\left(\beta=1.5, t_{18}=1.31, \mathrm{p}=0.2\right)$. At the wave-exposed site, however, dislodgement force was relatively greater for larger foot areas $(\beta=2.0$, $\left.t_{19}=2.08, p=0.05\right)$. This means that for snails from the wave-exposed site, larger foot areas required disproportionately greater dislodgement force (i.e. larger foot areas had greater tenacity).

Although highly variable, the mean dislodgement force did not differ between sites (ANOVA: $F_{(1,40)}=$ $0.31, p=0.58$ ). At both sites the allometric coefficient for the relationship between MPSA and dislodgement force was not significantly different from 1 (protected: $b=0.96, t_{18}=-0.15, \mathrm{p}>0.50 ;$ wave-exposed: $b=1.16$, $t_{19}=0.52, \mathrm{p}>0.50$ ) and dislodgement force increased with MPSA at the same rate (ANCOVA, Table 1; Fig. 5b). There was one difference between sites revealed by this analysis: the size-specific dislodgement force was greater for the wave-exposed snails than the protected snails (ANCOVA, Table 1; Fig. 5b).

\section{DISCUSSION}

Intertidal organisms exhibit various behavioral, morphological and physiological traits that aid in coping (a)

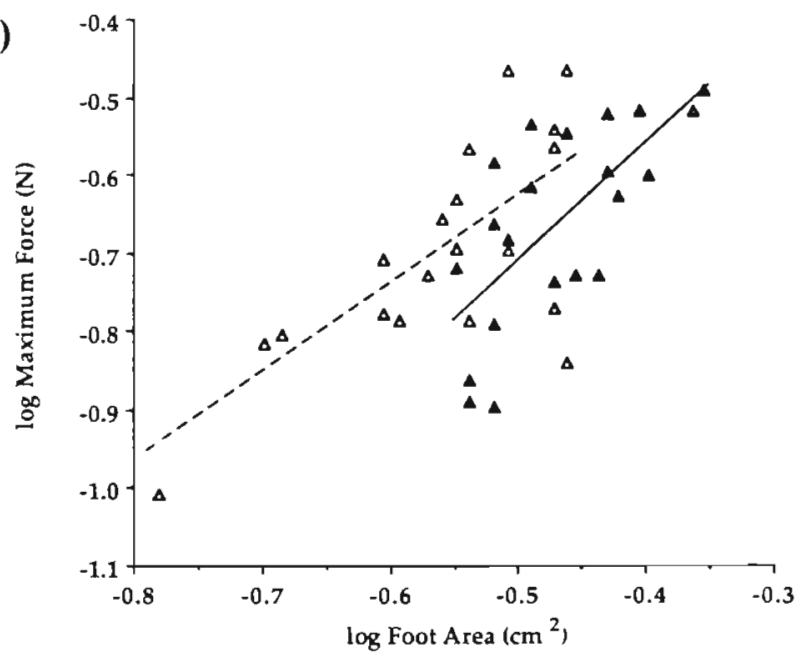

(b)

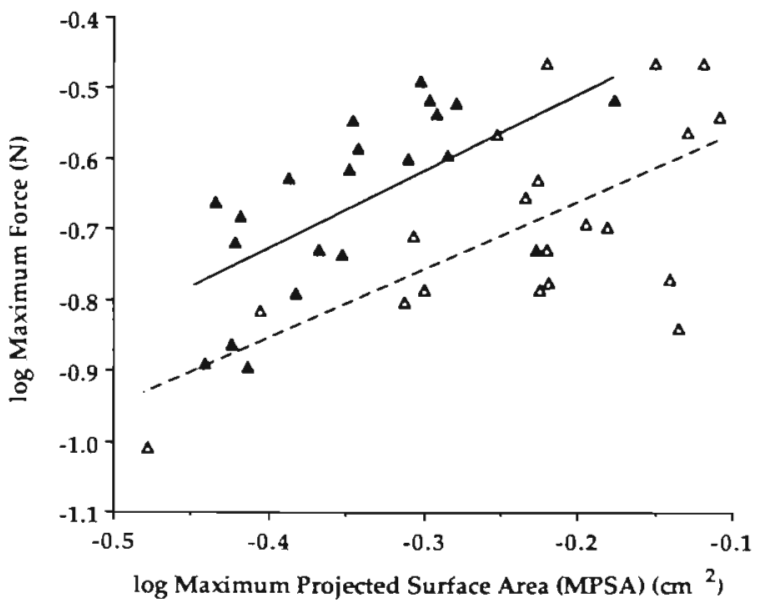

Fig. 5. Littorina obtusata. (a) Log-log plot of dislodgement force $(N)$ as a function of mean foot area $\left(\mathrm{cm}^{2}\right)$ of snails from the protected site $(\Delta,-\cdots)$ and the wave-exposed site $(\mathbf{\Lambda},-\mathbf{-})$. Lines represent the uncorrected least squares regressions for data from each site (see Table 1 for corrected linear regression statistics). (b) Log-log plot of dislodgement force (N) as a function of MPSA $\left(\mathrm{cm}^{2}\right)$ of snails from the protected site $(\Delta,-\cdots)$ and the wave-exposed site $(\Lambda,-)$. Lines represent least squares regressions for data from each site. Slopes of lines do not differ significantly; elevations of lines are significantly different (see Table 1 for ANCOVA and linear regression statistics)

with wave-imparted hydrodynamic forces. Waveimparted forces, by dislodging intertidal organisms, may determine an individual's ability to persist in the intertidal zone. Snails can reduce the likelihood of wave-induced dislodgement by using sheltered microhabitats, altering the morphology of their shells in ways that reduce hydrodynamic forces (Branch \& Marsh 1978), or by increasing the force with which they adhere (Kitching et al. 1966, Etter 1988a, Stebbins 
1988). We examined shell and foot characteristics of the herbivorous, intertidal snail Littorina obtusata and found differences in shell morphology, foot area and tenacity that were not only associated with wave-exposure and snail size but which are also likely to have an important role in resisting dislodgement.

Hydrodynamically induced dislodgement forces experienced by Littorina obtusata should be greater for larger snails as well as for snails inhabiting more waveexposed habitats. Alterations in the drag experienced by snails can be achieved morphologically by changes in shape or size (represented by $C_{D}$ and MPSA respectively; Eq. 1). We found: (1) that there were differences in size and shape between populations; and (2) that within both populations there were size-related differences in shell shape. The shells of wave-exposed snails were smaller and relatively short compared to protected snails of similar shell size (MPSA). Similarly, shells from both sites were relatively short as shells increased in length. Constructing shorter, smaller, more elongate shells probably lowers the risk of waveinduced dislodgement for 2 reasons.

First, shell height and size (MPSA) may influence the availability of sheltered microhabitats (sensu Kohn 1971, Emson \& Faller-Fritsch 1976, Raffaelli \& Hughes 1978). Taller shells might exclude individuals from shelter, forcing them to bear the brunt of free-stream flow and thereby increasing their likelihood of dislodgement. The use of cracks and crevices is common among intertidal snails on wave-exposed shores and has been reported for Thais (= Nucella) canaliculata, T. emarginata, Littorina scutulata (Denny et al. 1985), N. lapillus (Menge 1978, Etter 1988a), and Acanthina angelica (Lively 1986). Second, decreased size (MPSA) as well as changes in shape may decrease drag and thereby decrease the likelihood of dislodgement in a given flow (Eq. 1). Shorter, more elongate shells, for example, are likely to have a lower coefficient of drag. Thus, high drag environments may exert selection for smaller, shorter, more elongate shells.

In contrast, it appears that shell height and size were less important in reducing the likelihood of waveinduced dislodgement on the protected shore. Although increased height and MPSA are likely to increase drag in a given flow, these features may also act to deter predation by Carcinus maenas or to decrease rates of desiccation. These hypotheses have yet to be tested for Littorina obtusata.

Dislodgement can be reduced not only by changing shell morphology, but also by increasing the force required to dislodge; increased dislodgement force can be attained by increasing foot area or tenacity. The present analysis indicates that foot area was disproportionately smaller for larger snails on both shores (i.e. $b<1.0$ ), implying that the risk of dislodgement in- creased with size in these snails. Two characteristics of wave-exposed snails, however, indicate that they may be able to compensate for this increased risk. First, wave-exposed snails were shorter and more elongate. This shape difference may partially offset the mechanical consequences associated with faster flows; that is, shorter shells are likely to have both lower drag coefficients as well as greater access to protected cracks. Second, tenacity of wave-exposed snails increased with increasing foot area. These data suggest that there may be compensating trade-offs in the shell shape, foot area and tenacity of wave-exposed Littorina obtusata.

Greater force was required to dislodge waveexposed snails of a given size because their sizespecific foot area was greater than that of protected snails. Similar results regarding intraspecific variation in foot area in habitats of different wave exposures have been reported for Nucella lapillus in the British Isles (Kitching et al. 1966) and $N$. lapillus on New England shores (Etter 1988a). Increases in foot area may be a developmentally plastic response elicited by wave-exposed snails that allows them to reduce the likelihood of dislodgement. Wave activity characteristic of the protected shore, however, may not be intense enough to induce the development of larger foot areas. Etter (1988a), for example, found that when he transplanted juvenile $N$. lapillus from protected to waveexposed shores they developed larger foot areas than non-transplanted controls.

Alternatively, predation may be a mechanism responsible for directing the development of smaller foot areas on protected shores. Predation on Littorina obtusata by green crabs Carcinus maenas has been documented in the laboratory (Trussell unpubl. data) and field (Seeley 1986). If relatively larger foot areas developed on protected shores, the foot mass extending beyond the perimeter of the aperture of the protective shell might make $L$. obtusata more vulnerable to crab predation. Moreover, increased visceral mass associated with larger foot areas is likely to reduce the snail's ability to retract into the shell, thereby making the snail more vulnerable to apertural probing by crabs (Palmer 1990). Finally, larger foot areas may increase physiological stress, such as desiccation, on protected shores (Vermeij 1971a, b, 1973, Etter 1988b). These scenarios may lead to selection for relatively smaller foot areas on protected shores.

Surprisingly, tenacity was significantly greater for snails from the protected shore. Tenacity is influenced by the surface area of the foot, and the thickness and viscoelastic nature of the foot mucus (Branch \& Marsh 1978, Grenon \& Walker 1981, Denny 1984, Etter 1988a). Differences in tenacity and the mechanisms modulating tenacity between shores differentially 
exposed to wave action are not well understood. Intuitively, one would expect that tenacity should increase with wave exposure. For example, Branch \& Marsh (1978) found that tenacity in 6 species of patellid limpets increased with corresponding increases in wave exposure. Etter (1988a), however, found that tenacity in Nucella lapillus did not differ between shores of different wave-exposure. Because the differences in dislodgement forces between shores were determined primarily by foot area, and since mean tenacity did not differ between shores, Etter (1988a) also suggested that it is likely that the viscoelastic nature and thickness of the foot mucus were similar between shores. The results presented here suggest otherwise for Littorina obtusata, and are, to the best of our knowledge, the first demonstration of greater tenacity on a protected shore.

The mechanisms modulating tenacity are likely to be different on shores of different wave-exposure. On wave-exposed shores, wave activity is likely to be the primary mechanism regulating snail tenacity. On protected shores, however, greater snail tenacity may reduce the success of predators. If, as suggested earlier, predation is an important selective force favoring smaller foot areas on protected shores, then perhaps increased tenacity may function to compensate for smaller foot areas.

Alternatively, perhaps differences in substratum use promote differences in tenacity between shores of different wave exposure. Snails at the wave-exposed site were found primarily in cracks and crevices or on bare substratum while snails at the protected site were typically found on Ascophyllum nodosum. Increased tenacity at the protected shore may function to increase adhesion on this relatively slippery algal substratum.

In conclusion, this study suggests that wave exposure plays a role in shaping intraspecific variation in the shell and foot characteristics of Littorina obtusata. High drag environments appear to favor snails with smaller, shorter, more elongate shells. This morphology may function both to increase a snail's ability to exploit microhabitats sheltered from direct wave surge as well as to reduce the overall drag experienced by a shell in a given flow. High wave activity may also induce the development of larger foot areas thereby allowing individuals inhabiting these environments to resist greater dislodgement forces. Tenacity differed between shores, and it is possible that predation and substratum affinity may be important factors regulating foot size and tenacity on protected shores. The work presented here suggests that shell morphology, foot area and tenacity have important roles in mitigating wave-induced dislodgement in the intertidal snail L. obtusata.
Acknowledgements. The comments of O. Ellers, R. Etter, S. Gaines, C. Kresja, P. Levin, R. Olson, P. Sale, B. Sobczak, and $N$. Wheelwright contributed substantially to this manuscript and are greatly appreciated. M. Denny and an anonymous reviewer were especially helpful in improving our presentation of the data. J Taylor and R. Etter provided valuable statistical advice. We thank S. Welsh and C. Zartman for help in the field and $\mathrm{C}$. Chester for the snail drawings. This work was supported by a SURDNA Undergraduate Research Foundation Fellowship to G.C.T and N.S.F. Research Planning Grant OCE 90-09763 to A.S.J.

\section{LITERATURE CITED}

Branch, G. M., Marsh, A. C. (1978). Tenacity and shell shape in six Patella species: adaptive features. J. exp. mar. Biol. Ecol. 34: 111-130

Dalby, D. H., Cowell, E. B., Syratt, W. J. (1978). An exposure scale for marine shores in western Norway. J. mar. biol. Ass. U.K. 58: 975-996

Denny, M. W. (1983). A simple device for recording the maximum force exerted on intertidal organisms. Limnol. Oceanogr. 28: 1269-1274

Denny, M. W. (1984). Mechanical consequences of pedal mucus and their consequences for gastropod structure and performance. Am. Zool. 24:23-26

Denny, M. W. (1985). Wave forces on intertidal organisms: a case study. Limnol. Oceanogr. 30: 1171-1187

Denny, M. W. (1989). A limpet shell shape that reduces drag: laboratory demonstration of a hydrodynamic mechanism and an exploration of its effectiveness in nature. Can. J. Zool. 67: 2098-2106

Denny, M. W., Daniel, T. L., Koehl, M. A. R. (1985). Mechanical limits to size in wave-swept organisms. Ecol. Monogr. 55: 69-102

Denny, M. W. Gaines, S. D. (1990). On the prediction of maximal intertidal wave forces. Limnol. Oceanogr. 35: 1-15

Dudgeon, S. R., Johnson, A. S. (1992). Thick versus thin: thallus morphology and tissue mechanics influence differential drag and dislodgement of two co-dominant seaweeds. J. exp. mar. Biol. Ecol. 165: 23-43

Emson, R. H., Faller-Fritsch, R. J. (1976). An experimental investigation into the effect of crevice availability on abundance and size structure in a population of Littorina rudis (Maton): Gastropoda: Prosobranchia. J. exp. mar. Biol. Ecol. 23: 285-297

Etter, R. J. (1988a). Asymmetrical developmental plasticity in an intertidal snail. Evolution 42: 322-334

Etter, R. J. (1988b). Physiological stress and color polymorphism in the intertidal snail Nucella lapillus. Evolution 42: $660-680$

Etter, R. J. (1989). Life history variation in the intertidal snail Nucella lapillus across a wave exposure gradient. Ecology 70: $1857-1876$

Fuller, W. A. (1987). Measurement error models. John Wiley \& Sons, New York

Grenon, J.-F., Walker, G. (1981). The tenacity of the limpet, Patella vilgata L.: an experimental approach. J. exp. mar. Biol. Ecol. 54: 277-308

Judge, M. L. (1988). The effects of increased drag on Lottia gigantea (Sowerby 1834) foraging behavior. Funct. Ecol. 2: $363-369$

Kitching, J. A., Muntz, L., Ebling, F. J. (1966). The ecology of Lough Ine. XV. The ecological significance of shell and body forms in Nucella. J. Anim. Ecol. 35: 113-126

Kohn, A. J. (1971). Diversity, utilization of resources, and 
adaptive radiation in shallow-water marine invertebrates of tropical oceanic islands. Limnol. Oceanogr. 16: 332-348

LaBarbera, M. (1989). Analyzing body size as a factor in ecology and evolution. A. Rev. Ecol. Syst. 20: 97-117

Lively, C. M. (1986). Predator-induced shell dimorphism in the acorn barnacle Chthamalus anisopoma. Evolution 40: $232-242$

Lubchenco, J., Menge, B. A. (1978). Community development and persistence in a low rocky intertidal zone. Ecol. Monogr. 59: 67-94

Menge, B. A. (1974). Effects of wave action and competition on brooding and reproductive effort in the seastar Leptasterias hexactis. Ecology 55: 84-93

Menge, B. A. (1976). Organization of the New England rocky intertidal community: role of predation, competition, and environmental heterogeneity. Ecol. Monogr. 46: 355-393

Menge, B. A. (1978). Predation intensity in a rocky intertidal community. Relation between predator foraging activity and environmental harshness. Oecologia 34: 1-16

Menge, B. A., Sutherland, J. P. (1976). Species diversity gradients: synthesis of the roles of predation, competition, and temporal heterogeneity. Am. Nat. 110: 351-369

Menge, B. A., Sutherland, J. P. (1987). Community regulation: variation in disturbance, competition, and predation in relation to environmental stress and recruitment. Am. Nat. 130: $730-757$

Miller, S. L. (1974). Adaptive design of locomotion and foot form in prosobranch gastropods. J. exp. mar. Biol. Ecol. 14: $99-156$

Paine, R. T., Levin, S. A. (1981). Intertidal landscapes: disturbance and the dynamics of pattern. Ecol. Monogr. 51: $145-178$

Palmer, A. R. (1990). Effect of crab effluent and scent of damaged conspecifics on feeding, growth, and shell morphology of the Atlantic dogwhelk Nucella lapillus (L.). Hydrobiologia 193: 155-182

This article was presented by $K$. L. Heck Jr, Dauphin Island, Alabama, USA
Raffaelli, D. G., Hughes, R. N. (1978). The effect of crevice size and availability on populations of Littorina rudis and Littorina neritoides. J. Anim. Ecol. 74: 71-83

Schmidt-Neilsen, K. (1984). Scaling: why is animal size so important? Cambridge University Press. Cambridge

Seeley, R. H. (1986). Intense natural selection caused a rapid morphological transition in a living marine snail. Proc. natl Acad. Sci. 80: 6897-6901

Sousa, W. P. (1979). Experimental investigations of disturbance and ecological succession in a rocky intertidal algal community. Ecol. Monogr. 49: 227-254

Sousa, W. P. (1984). The role of disturbance in natural communities. A. Rev, Ecol. Syst. 15: 353-391

Stebbins, T. D. (1988). Variable population structure and tenacity in the intertidal chiton Katharina tunicata (Mollusca: Polyplacophora) in northern California. Veliger 30: $351-357$

Underwood, A. J. (1981). Techniques of analysis of variance in experimental marine biology and ecology. Oceanogr. mar. Biol. A. Rev. 19: 513-605

Vermeij, G. (1971a). Temperature relationships of some tropical Pacific intertidal gastropods. Mar. Biol. 10: 308-314

Vermeij, G. (1971b). Substratum relationships of some tropical Pacific intertidal gastropods. Mar. Biol. 10:315-320

Vermeij, G. (1973). Morphological patterns in high-intertidal gastropods: adaptive strategies and their limitations. Mar. Biol. 20: 319-346

Vogel, S. (1981). Life in moving fluids. Princeton University Press, Princeton

Whalon, B. J. (1989). The role of wave exposure and predation in controlling shell color and morphology in the dogwhelk Nucella lapillus. Senior honors thesis, Bowdoin College

Witman, J. D. (1985). Refuges, biological disturbance, and rocky subtidal community structure in New England. Ecol. Monogr. 55: 421-445

Manuscript first received: July 30, 1992

Revised version accepted: June 7, 1993 